\title{
Knowing the past to predict the future: land-use change and the distribution of invasive bullfrogs
}

\author{
GENTILEFRANCESCO FICETOLA*†, LUIGI MAIORANO $₫ \S$, ALESSANDRA FALCUCCI \\ NICOLAS DENDONCKER-, LUIGI BOITANIt, EMILIOPADOA-SCHIOPPA*, CLAUDE \\ MIAUD† and WILFRIED THUILLER\| \\ *Dipartimento di Scienze dell' Ambiente e del Territorio, Università di Milano-Bicocca. Piazza della Scienza 1, 20126 Milano, \\ $\dagger$ Laboratoire d'Ecologie Alpine, UMR CNRS 5553, Université de Savoie, 73376 Le Bourget du Lac cedex, France, †Dipartimento di \\ Biologia Animale e dell'Uomo, Sapienza Università di Roma, viale dell'Università 32, 00185 Roma, Italy, §Department of Ecology \\ and Evolution, University of Lausanne, Biophore Building, CH-1015 Lausanne, Switzerland, - Centre for the Study of \\ Environmental Change and Sustainability, University of Edinburgh, Drummond Street, EH89XP Edinburgh, UK, \|Laboratoire \\ d'Ecologie Alpine, UMR CNRS 5553, Université Joseph Fourier, Grenoble Cedex 9, France
}

\begin{abstract}
Biological invasions and land-use changes are two major causes of the global modifications of biodiversity. Habitat suitability models are the tools of choice to predict potential distributions of invasive species. Although land-use is a key driver of alien species invasions, it is often assumed that land-use is constant in time. Here we combine historical and present day information, to evaluate whether land-use changes could explain the dynamic of invasion of the American bullfrog Rana catesbeiana (=Lithobathes catesbeianus) in Northern Italy, from the 1950s to present-day. We used MAXENT to build habitat suitability models, on the basis of past (1960s, 1980s) and present-day data on land-uses and species distribution. For example, we used models built using the 1960s data to predict distribution in the 1980s, and so on. Furthermore, we used land-use scenarios to project suitability in the future. Habitat suitability models predicted well the spread of bullfrogs in the subsequent temporal step. Models considering land-use changes predicted invasion dynamics better than models assuming constant land-use over the last 50 years. Scenarios of future land-use suggest that suitability will remain similar in the next years. Habitat suitability models can help to understand and predict the dynamics of invasions; however, land-use is not constant in time: land-use modifications can strongly affect invasions; furthermore, both land management and the suitability of a given land-use class may vary in time. An integration of land-use changes in studies of biological invasions can help to improve management strategies.
\end{abstract}

Keywords: alien invasive species, amphibians, future scenarios, habitat suitability models, invasion dynamics, long term monitoring, Rana catesbeiana, temporal dynamics

Received 17 February 2009 and accepted 05 April 2009

\section{Introduction}

Biological invasions are an unprecedented form of global change (Ricciardi, 2007), with alien invasive species (AIS) being a major issue for biodiversity conservation at the global scale (Sala et al., 2000; Thuiller, 2007). AIS can negatively impact native species via

Correspondence: Gentile Francesco Ficetola, Dipartimento di Scienze dell' Ambiente e del Territorio, Università di MilanoBicocca. Piazza della Scienza 1, 20126 Milano, Italy, tel. + 39 (0)2 64 4829 45, fax 39 (0)2 644829 96, e-mail: francesco.ficetola@unimi.it predation, competition and diffusion of diseases. Moreover, AIS can strongly affect the environment, for example by modifying ecosystem functioning and abiotic features (Strayer et al., 2006; Ricciardi, 2007). Some AIS are now present in multiple continents, due to the interplay between human-assisted diffusion and natural dispersal ability. This is causing a global homogenization of faunas and floras, with important effects on biodiversity pattern at both local scales and worldwide (McKinney \& Lockwood, 1999; Olden et al., 2004, 2008; McKinney, 2006; Quian \& Ricklefs, 2006). 
The eradication of established AIS can be a difficult and expensive task (Hulme, 2006). If prevention was ineffective, the most effective option is often restricting the spread when the invasions are at their earlier stages. Much attention is therefore devoted to the understanding of the dynamic of invasions, to set up plans of biological screening and prevention in the areas that are most at risk of invasion (Hulme, 2006). Predictive models are therefore used to evaluate the areas most at risk of invasion based on environmental features recorded at both local and global scale, including climate, land cover and distribution of other species (Le Maitre et al., 2008).

However, biological invasions are a dynamic process in which the temporal dimension cannot be overlooked. Environmental features change in time, species can quickly evolve in the new environment and these modifications can influence the invasion dynamics (Urban et al., 2008). Temporal change of climate is probably the dynamic feature most often integrated in models of biological invasions. Climate, in fact, is a major driver of environmental suitability for AIS, thus many recent studies used scenarios of future climate to project species distribution model and to predict the areas that might become suitable for AIS in the future (Roura-Pascual et al., 2004; Beaumont et al., 2009; Ficetola et al., 2009).

Climatic suitability is a key tool to predict invasion risk at coarse spatial scales, i.e., from countrywide to global (Roura-Pascual et al., 2004; Thuiller et al., 2005). However, suitable areas identified using bioclimatic models are often very large, including entire regions or countries and making it difficult to implement conservation plans (Heller \& Zavaleta, 2009). Climatic models should therefore be refined to identify smaller areas, with the integration of features recorded at finer scale (Ficetola et al., 2007a).

At finer spatial scales, land-use plays a major role in the dispersal and distribution of AIS. Land-use is obviously not independent from the distribution of human population, and AIS often take advantage of human modified environments (McKinney, 2006). Land-use is not constant in time, and can change quickly in response to socioeconomic factors (Falcucci et al., 2007). Common changes in land-use are the expansion of urban areas, conversion of natural vegetation to cropland and pasture or vice versa, and shift of agricultural practices to increase productivity (Leemans \& Zuidema, 1995; Petit \& Lambin, 2002; Hurtt et al., 2006). Multiple changes in land-use observed at local scale clearly have a global effect (Leemans \& Zuidema, 1995; Hurtt et al., 2006), and the change of land-use is probably the force most strongly affecting biodiversity of terrestrial and freshwater ecosystems (Sala et al., 2000) with important effects on conservation (Maiorano et al., 2008). Unfortunately, it is often difficult to have information on past land-use, and predicting future landuse can be challenging. In practice, most existing studies using models to predict the distribution of AIS implicitly assume a constant land-use in the past or in the future (Domenech et al., 2005 being a noticeable exception).

In this study, we incorporate dynamic land-use in suitability models, to predict the distribution of a problematic AIS, the American bullfrog Rana catesbeiana Shaw, 1802 (=Lithobates catesbeianus) at a regional scale. Bullfrog is native of eastern North America, but has been introduced in over 40 countries and four continents during the 20th century (Lever, 2003). Bullfrog is considered among the most harmful invasive species, because it can outcompete and predate native species (Blaustein \& Kiesecker, 2002; Kats \& Ferrer, 2003), can interact with predatory fish which further increase their negative effect on native amphibians (Blaustein \& Kiesecker, 2002), and it can spread diseases (Garner et al., 2006). Moreover, only a handful of founders can originate populations invading large areas in a few generations, with a spreading ability that challenges the traditional management plans (Ficetola et al., 2008). Plans are ongoing in several countries to prevent and control the spread of this species (Lever, 2003; Ficetola et al., 2007b; Kraus, 2009). Predictive models showed that climatic features are major drivers of the distribution of invasive bullfrog populations at coarse spatial scale (Ficetola et al., 2007a; Giovanelli et al., 2008), but also human activities and land-use can affect the invasion success of bullfrogs (Yiming et al., 2006; Ficetola et al., 2007a).

The bullfrog invasion in Northern Italy is documented since the 1930s (Lanza, 1962; Albertini \& Lanza, 1987). This represents a unique opportunity to evaluate the relationship between land-use changes and biological invasions. High quality distribution data cover 70 years of bullfrog expansion; furthermore, land-use information is available since the 1960s (Falcucci et al., 2007). This study combined historical information on land-use and bullfrog distribution, to evaluate whether land-use can explain bullfrog spread in the investigated area. The historical information allowed us to test whether models correctly predict the expansion of this species. Moreover, we used scenarios of future landuses (Rounsevell et al., 2006) to identify the areas that can be most at risk of invasion in the near future.

\section{Methods}

\section{Study area and distribution data}

We analysed bullfrog distribution in the Eastern River Po basin, Northern Italy (Fig. 1). The study area is a lowland dominated by agriculture, with numerous wetlands, and crossed by a dense network of water- 
(b)

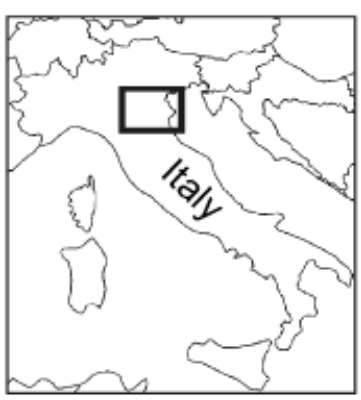

(d)
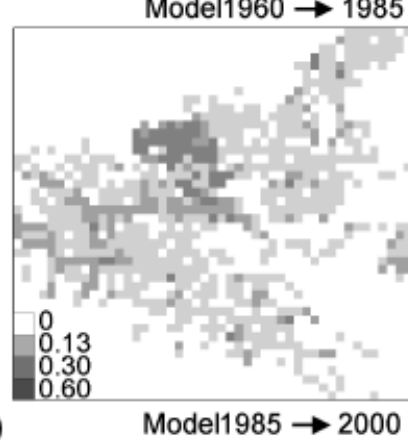

(a) Distribution 1960

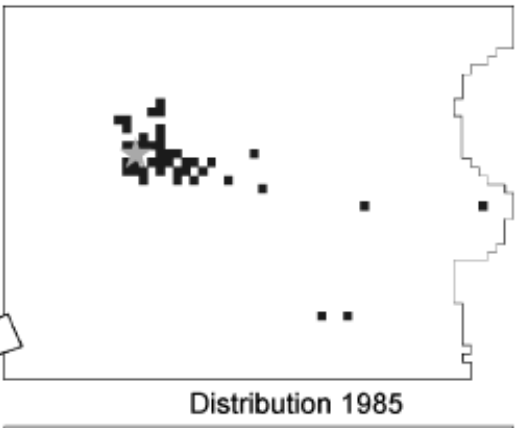

(c)
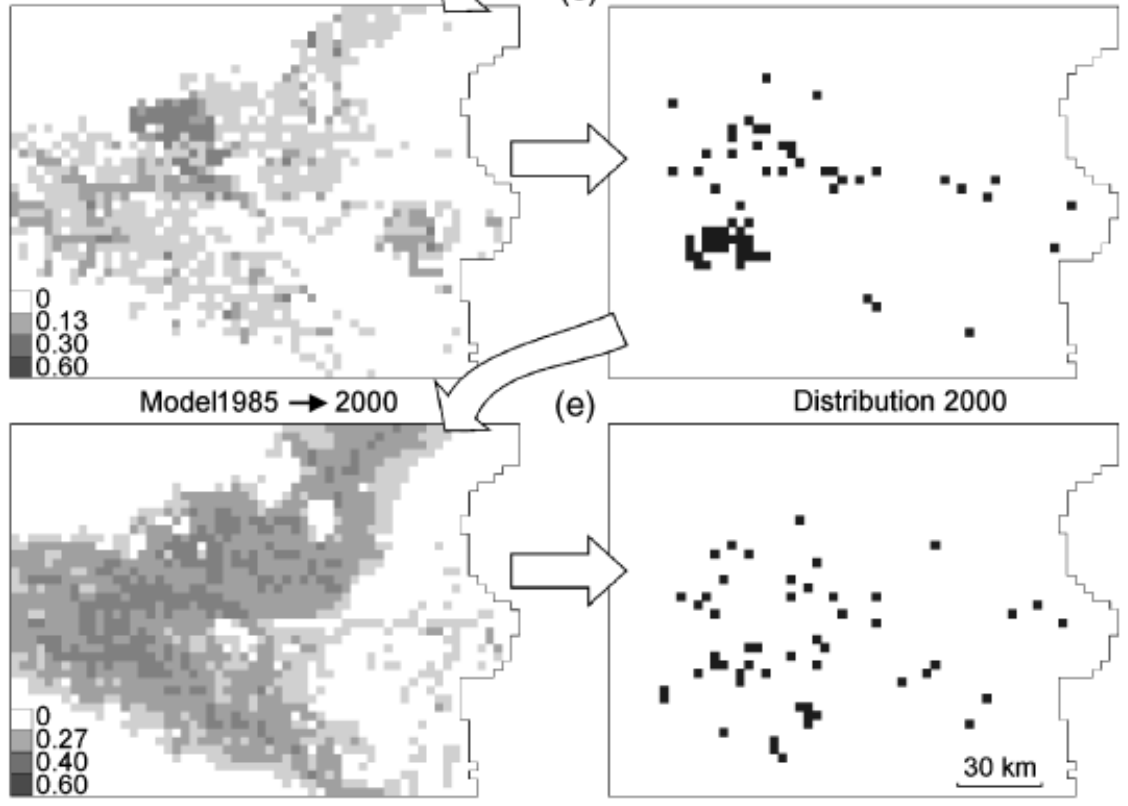

(e)

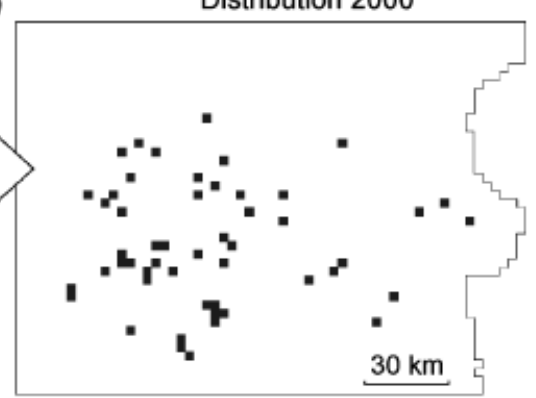

Fig. 1 (a, c, e): Observed distribution of bullfrogs in three temporal steps (1960, 1985 and 2000), and (b, d) suitability predicted using MAXENT models, based on the distribution observed in the previous temporal step, taking into account land-use change. The star in (a) represents the locality of first introduction. The different suitability thresholds $(0.13$ and 0.27$)$ correspond to the 10 th percentile training presence thresholds of models (Pearson et al., 2007).

courses and irrigation channels. This is the region of Europe where bullfrogs are present over the largest area (Ficetola et al., 2007b). Historical information indicates that a handful of bullfrogs have been first introduced in a single locality (Fig. 1a) in a single event, during the 1930s (between 1932 and 1937: Albertini, 1970); genetic analyses confirmed a single introduction of very few individuals (Ficetola et al., 2008). For the period 19371986, we obtained point data on bullfrog distribution from the literature (Lanza, 1962; Albertini, 1970, 1983; Albertini \& Lanza, 1987). These authors monitored the spread of bullfrogs using a combination of field surveys over the whole study area and interviews of local people. For the period 1986-2007, we used an updated version of the database of Ficetola et al (2007a). We then divided the invasion in three temporal steps, corresponding to the time frames covered by the available land-use data: (1) 1937-1965 (98\% of data collected during 1952-1965), hereafter: Distrib1960; (2) 19671985 (the majority of data collected during the 1980s), thereafter: Distrib1985; (3) 1987-2007 (95\% of data collected after 1990), thereafter: Distrib2000. Modifications of the temporal windows by $2-3$ years would produce identical distributions.

\section{Past land-use}

We used three land-use/land-cover maps covering the study area and spanning the time frame 1960-2000. The oldest map (geographic scale 1:200000; legend of 22 classes) was produced by the National Research Council using cadastral datasets collected during the period 1956-1968. We will refer to this map as the 'Map1960'. The 1985 and the 2000 land-use maps (hereafter: Corine1985 and Corine2000) are part of the Corine Land Cover program started in 1985 by the European Com- 
munity to generate digital land-use/land-cover maps covering the European continent. These two maps, produced using satellite images taken during late 1980s and 1999-2001, respectively (Buttner et al., 2004), have a legend of 44 classes and a spatial detail comparable to that of a paper map on a scale of $1: 100000$. The map obtained using images taken during late 1980s is usually referred to as Corine1990. However, in this study we name it Corine1985 for consistency with the available distribution data. A more detailed description of the three maps can be obtained from Falcucci et al. (2007). To obtain a common legend (thematic generalization: Petit \& Lambin, 2002), we reclassified the three maps simplifying the legend already proposed by Falcucci et al. (2007) and considering five classes: crops (except rice fields), rice fields, forests, artificial areas, inland water. Moreover, to obtain three spatially homogeneous layers, we used a Block Statistics function in ARCGIS $9.2\left(\right.$ ESRI $\left.^{(}\right)$, Redlands, CA, USA), producing three raster maps ( $3 \mathrm{~km}$ cell size) indicating for each pixel the percentage occupied by each land-use/land-cover class.

\section{Future land-use}

Scenarios of future (2020) land-use change were developed by previous studies (Rounsevell et al., 2006) on the basis of an interpretation of five alternative storylines of the ALARM project (Spangenberg, 2007), representing different assumptions about demographic changes, technological and socioeconomic development (Nakicenovic \& Swart, 2000). The five scenarios where: GRAS, a future world orientated towards economic growth approximating the scenario A1F1 of International Panel on Climate Change special report on emission scenarios (SRES); BAMBU ( = A2 SRES), a continuation into the future of currently known socioeconomic and policy strategies; BAMBU-SEL, the same as BAMBU plus shock in energy price level; BAMBU-CANE, the same as BAMBU plus contagious natural epidemic; SEDG ( = B1 SRES), a scenario focused on the achievement of sustainable development. The scenarios were downscaled at the spatial resolution of Corine2000 $(250 \mathrm{~m})$ using a mix of spatial multinomial logistic regression and Bayesian statistics (Dendoncker et al., 2006). Further details are described elsewhere (Dendoncker et al., 2006; Rounsevell et al., 2006). For the purpose of this study, future land-uses were aggregated to $3 \mathrm{~km}$ resolution raster maps, as described for the past land-uses.

\section{Data analysis}

We modelled environmental suitability using MAXENT 3.2.1 (Phillips et al., 2006; Phillips \& Dudík, 2008).
MAXENT is a machine learning method that estimates the distribution of a species by finding the probability distribution of maximum entropy, subject to constraints representing our incomplete information about the distribution. The constraints are that the expected value of each environmental variable should match its average over sampling locations derived from environmental layers (Phillips et al., 2006). The model evaluates the suitability of each grid cell as a function of environmental variables. MAXENT requires presence-only data, and can calculate the relative importance of different environmental features (Phillips et al., 2006). We used a logistic output of MAXENT, with suitability values ranging from 0 (unsuitable) to 1 (optimal habitat) (Phillips \& Dudík, 2008). In recent comparisons, MAXENT was among the most effectives methods of species distribution modelling, and showed high quality performance with both small and large sample sizes (Elith et al., 2006; Wisz et al., 2008). The reliability of MAXENT has been confirmed by its capacity to predict the outcome of introductions of invasive species outside the native range (Ficetola et al., 2007a) and novel presence localities for poorly known species (Pearson et al., 2007).

We used the following procedure to evaluate the role of land-use in the bullfrog invasion. First, for each temporal step, we used MAXENT to build a model relating species distribution to land-use (per pixel: cropland $\%$; rice field $\%$, forest $\%$, artificial areas $\%$, inland water $\%$ ) and altitude (average altitude obtained from a digital terrain model with $20 \mathrm{~m}$ cell size). We did not include climatic features, since coarse scale models showed that the whole study area has very high climatic suitability (Ficetola et al., 2007a); models including scenarios of climate change suggest that climatic suitability within the study area will remain high in the future (G. F. Ficetola, unpublished results). We did not include water bodies distribution because the small wetlands used by bullfrogs (e.g., ditches, ponds) are not recorded at the resolution of the historical and future land-uses; small water bodies used for irrigation are present at high density in the areas with rice fields or croplands. We included altitude as it can influence frog dispersal and the features of water bodies (e.g., slow stream ditches are only present in lowlands). We developed each model using linear, quadratic and hinge functions (Phillips \& Dudík, 2008). Then, we used the land-use of the subsequent temporal step to predict the new bullfrog distribution (See Table 1). Therefore, we built suitability model for Distrib1960 using the Map1960 (Model1960); then we used Corine1985 to project suitability in the subsequent temporal step (Model1960 $\rightarrow$ 85) (Table 1, Fig. 1a and b). Similarly, we built the model for Distrib1985 using Corine1985 (Model1985); then we used Corine2000 to project 
Table 1 Distribution data and environmental layers used to build the models predicting bullfrog expansion

\begin{tabular}{llll}
\hline Model & & \multicolumn{2}{l}{ Environmental layers } \\
\cline { 4 - 4 } & Input data & For model calibration & For model projection \\
\hline Model1960 & Distrib1960 & Map1960 & Map1960 \\
Model1960 $\rightarrow 1985$ & Distrib1960 & Map1960 & Corine1985 \\
Model1985 & Distrib1985 & Corine1985 & Corine1985 \\
Model1985 $\rightarrow 2000$ & Distrib1985 & Corine1985 & Corine2000 \\
Model2000 & Distrib2000 & Corine2000 & Corine2000 \\
Model2000 $\rightarrow 2020$ & Distrib1985 & Corine2000 & 5 future scenarios \\
\hline
\end{tabular}

See the text for the acronyms.

suitability (Model1985 $\rightarrow$ 2000) (Table 1, Fig. 1c and d). Finally, we built the model for Distrib2000 using Corine2000 (Model2000) and we projected the suitability into the future using the five 2020 scenarios (Table 1). Rice fields where a category not available in the future scenarios, therefore for Model2000 we pooled rice fields with other croplands. Pooling rice fields with croplands did not affect these models, because the models based on Corine2000, pooling or not pooling rice fields with croplands, were identical (results not shown). In each model, we assumed that a cell was suitable for bullfrog presence if its suitability score was greater than the 10th percentile of training presence points (Pearson et al., 2007). We then examined the omission and commission error of models to evaluate their predictive performance (Jiménez-Valverde et al., 2008).

We restricted our analysis to an area of high bioclimatic suitability $(180 \mathrm{~km} \times 132 \mathrm{~km})$ individuated by Ficetola et al. (2007a), surrounding the introduction point. Genetic data showed that bullfrog dispersion can occur at this spatial scale (Austin et al., 2004). As there are no major barriers for dispersion (e.g., mountains), we assume that the whole area can be potentially colonized in a few generations.

We used two methods to evaluate the ability of our models to predict the bullfrog spread. First, we used a $\chi^{2}$ test $(1 \mathrm{df})$ to compare observed frequencies of correct and incorrect predictions, and therefore to evaluate if our models predict distribution in the subsequent temporal step significantly better than expected under random expectations (Roura-Pascual et al., 2004). Second, we built logistic regression models relating the observed bullfrog distribution in a temporal step to the suitability predicted on the basis of the two models built for the previous step (e.g., we predicted Distrib1985 on the basis of either Model1960 and Model1960 $\rightarrow$ 85). We assessed significance of the logistic regression using likelihood ratio. We then used an information-theory approach, based on Akaike Information Criterion (AIC) to compare the relative ability of models (Burnham \& Anderson, 2002), and therefore to evaluate if taking into account land-use changes actually improves model predictions. This analysis assumes pseudo-absences in cells where bullfrogs have not been observed. Despite that pseudo-absences are not always reliable (Engler et al., 2004), we used this approach to compare the performance of different models on the same distribution data, therefore the bias caused by pseudo-absences was constant between models compared.

\section{Results}

During the period 1937-1965, bullfrogs were recorded in 43 pixels $(3 \mathrm{~km} \times 3 \mathrm{~km})$ (Fig. 1a); most of presence localities were clumped close to the introduction locality. During the period 1966-1986, bullfrogs' distribution was less clumped and the species was present in 64 pixels. During the period 1987-2007, bullfrog presence has been recorded in 51 pixels.

\section{Predicting the past invasion}

The model built for 1960s showed that bullfrog presence was associated to high rice fields $\%$, low elevation, intermediate/high cropland $\%$, and intermediate levels of forest $\%$; rice field $\%$ was the variable with the largest contribution (56\% of explained variation) (Table 2). Model1960 $\rightarrow 85$ predicted an expansion of areas suitable for bullfrogs, mostly south-east to the area of introduction. The observed bullfrog expansion followed the same overall pattern predicted by the model (Fig. 1b and $\mathrm{c}$ ).

The model built using Distrib1985 showed that bullfrogs were associated to intermediate/high cropland\% and low elevation (Table 2). In this model, rice fields and forest $\%$ explained only a minor percentage of variation (3\% or less). Model1985 $\rightarrow 2000$ predicted an expansion of areas suitable for bullfrogs, mostly in the southern and in the northern part of the study area (Fig. 1d and e). Distrib2000 only slightly expanded the area of occurrence observed in Distrib1985. Nevertheless, it should be noted that the localities with new 
Table 2 Predictive performance of models, evaluated by examining omission and commission errors

\begin{tabular}{|c|c|c|c|c|c|c|c|c|}
\hline \multirow[b]{2}{*}{ Model } & \multirow[b]{2}{*}{ Environmental variables* } & \multirow[b]{2}{*}{$\begin{array}{l}\text { test } \\
N\end{array}$} & \multicolumn{2}{|c|}{ Omission error } & \multicolumn{2}{|c|}{ Commission error } & \multirow[b]{2}{*}{$\chi^{2}$} & \multirow[b]{2}{*}{$P$} \\
\hline & & & $\begin{array}{l}\text { Pres. } \\
\text { correct }\end{array}$ & $\begin{array}{l}\text { Pres. } \\
\text { incorrect }\end{array}$ & $\begin{array}{l}\text { Abs. } \\
\text { correct }\end{array}$ & $\begin{array}{l}\text { Abs. } \\
\text { incorrect }\end{array}$ & & \\
\hline Model1960 & $\begin{array}{l}\text { Rice fields, elevation, cropland, } \\
\text { forest }\end{array}$ & 43 & $39(11)$ & $4(32)$ & 1837 (1809) & $581(609)$ & 99.6 & $<0.001$ \\
\hline Model1960 $\rightarrow 1985$ & & 64 & $47(20)$ & $17(44)$ & $1660(1633)$ & $737(764)$ & 52.3 & $<0.001$ \\
\hline Model1985 & Elevation, cropland & 64 & $58(34)$ & $6(30)$ & 1146 (1122) & $1251(1275)$ & 37.0 & $<0.001$ \\
\hline Model1985 $\rightarrow 2000$ & & 51 & $42(27)$ & $9(24)$ & 1158 (1142) & $1252(1267)$ & 18.5 & $<0.001$ \\
\hline Model2000 & Elevation, cropland & 51 & $45(26)$ & $6(25)$ & $1190(1171)$ & $1220(1238)$ & 28.3 & $<0.001$ \\
\hline
\end{tabular}

The table reports the correct and incorrect predictions of presence and absence, and Pearson's $\chi^{2}$ with $1 \mathrm{df}$ (Roura-Pascual et al., 2004). Suitability of each cell was based on the 10th percentile of training presence points (Pearson et al., 2007). In parenthesis, the values under random expectations.

*Variables accounting for $>5 \%$ of explained variation. The variables with the largest independent contributions are first in the lists.

Table 3 Relative performance of GLMs, based on MAXENT models, in predicting bullfrog expansion, evaluated using Akaike's Information Criterion (AIC)

\begin{tabular}{llll}
\hline $\begin{array}{l}\text { Distribution } \\
\text { to be predicted }\end{array}$ & $\begin{array}{l}\text { Includes } \\
\text { temporal } \\
\text { change? }\end{array}$ & Model & AIC \\
\hline Distrib1985 & Yes & Model1960 $\rightarrow$ 1985 & 549.6 \\
& No & Model1960 & 571.5 \\
Distrib2000 & Yes & Model985 $\rightarrow 2000$ & 480.06 \\
& No & Model1985 & 480.81 \\
\hline
\end{tabular}

The two models including temporal changes in environmental variables (Model1960 $\rightarrow$ 1985, Model1985 $\rightarrow$ 2000) are compared against models not including the temporal changes (Model1960, Model1985).

records are within the high probability areas predicted by Model1985 $\rightarrow 2000$ (Fig. 1d and e).

All models tended to predict well observed presence localities (Table 2). Conversely, all models tended to overpredict suitable areas, i.e., predicted suitability in a large number of pixels where bullfrog presence has not been recorded yet (Fig. 1, Table 2).

Using logistic regression, Model1960 $\rightarrow 1985$ predicted Distrib1985 significantly better than random expectations (likelihood ratio test, $\chi_{1}^{2}=47.845, P<0.001$ ). Its performance was much better than the one of the model not taking into account temporal change in environmental variables (difference in AIC, $\Delta$ AIC $=21.9) \quad($ Table 3$)$. Similarly, Model1985 $\rightarrow 2000$ predicted Distrib2000 significantly better than random expectations $\left(\chi_{1}^{2}=20.280, P<0.001\right)$. Its performance was better than that of the model not taking into account changes in environmental variables, but the difference was limited $(\triangle \mathrm{AIC}=0.75)$ (Table 3$)$. The small difference between the two models probably occurred because land-use and consequently suitability did not change considerably between 1980s and 2000 (Falcucci et al., 2007). For instance, the suitability predicted by Model1985 was very similar to that predicted by Model1985 $\rightarrow 2000 \quad(r=0.97)$. Conversely, land-use strongly changed from 1960 to 1985 (as described in Falcucci et al., 2007), and the correlation between Model1960 $\rightarrow 1985$ and Model1960 was weaker $(r=0.54)$.

\section{Scenarios of future invasion}

Model2000 was very similar to Model1985 (Figs 1 and 2, Table 2), and showed that bullfrogs were associated to intermediate and high cropland percentage and low elevation. As the previous models, Model2000 predicted presence with high accuracy, but predicted suitability in many pixels without bullfrog records (Table 2).

The projection using the 2020 scenarios did not show strong changes in suitability. The results were extremely similar among the five alternative scenarios, with only minor differences (Fig. 2). These results were essentially linked to the high stability in land-use projection predicted for our study area for the timeframe considered, where intensive agriculture is and will continue to be the dominant land-use class.

\section{Discussion}

Suitability models, based on land-use and distribution data, predicted the invasion of bullfrogs in Northern Italy relatively well. Our analysis used information collected in three subsequent temporal steps: we predicted bullfrog distribution in the 1980s using data collected during the 1960s; similarly, we predicted present-day distribution using the 1980s data. This approach is a true validation of the models; our results therefore provide a measure of the effectiveness of 
(a)

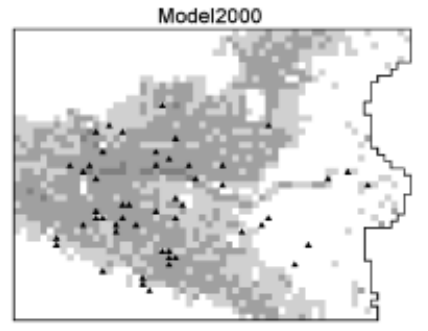

(b)

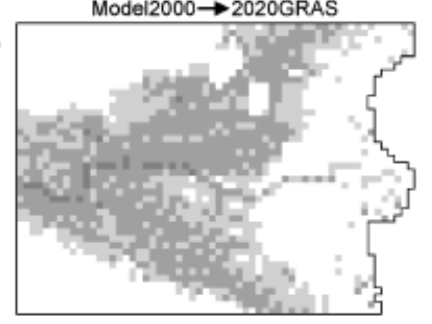

(c)

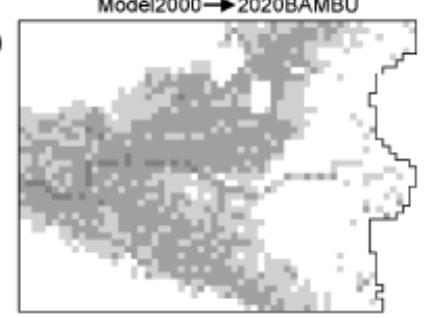

(d)

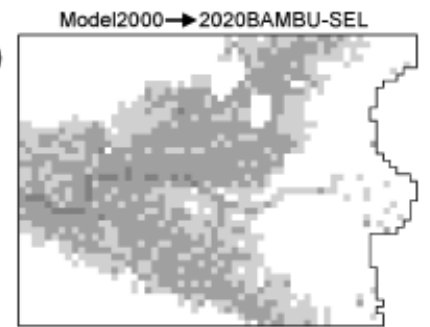

(e)

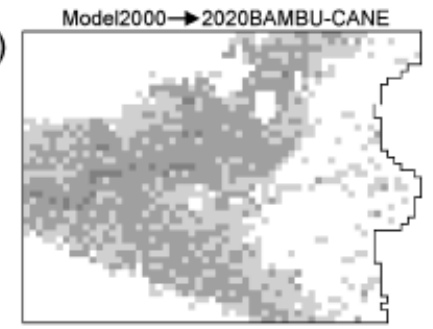

(f)

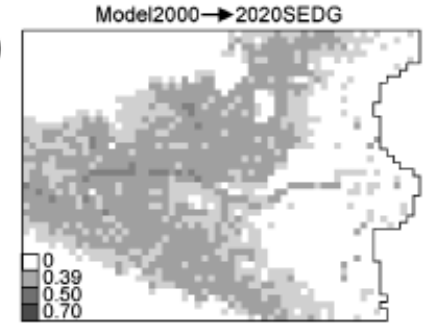

Fig. 2 (a) Observed distribution of bullfrog for the temporal step 2000, and environmental suitability of Model2000. (b-e): projected suitability in the future (2020) using five scenarios of land-use change. suitability models trying to predict the spread of invasive species. Habitat suitability models are often used for this task, with applications in risk assessment or in control strategies (e.g., Ward, 2007; Evangelista et al., 2008; Nielsen et al., 2008; Ficetola et al., 2009). However, long term historical data are seldom available (Loo et al., 2007; Vallecio et al., 2009), and it is therefore difficult to evaluate whether model predictions correspond to the actual invasion dynamics. Our analysis suggests that suitability models have a good performance in predicting invasions. Nevertheless, the comparison of predictions with the actual invasion dynamics reveals important points. First, the match between predicted suitability and invasion data was not perfect, highlighting potential issues. Second, the most important variables to explain the bullfrogs' distribution were not the same in the three temporal steps, confirming the complexity of extrapolating model results in time (Guisan \& Thuiller, 2005). Most importantly, despite altitude does not change in time, other environmental variables (land-use) are not constant in time; the incorporation of environmental changes in suitability models can be essential to correctly understand invasion dynamics.

\section{Models and real invasion: reliability and discrepancies}

The predictions of our models showed high sensitivity, i.e., most of presence records corresponded to high suitability pixels, on the basis of models developed in the previous temporal step (Table 2). Bullfrogs were strongly associated to lowland agricultural areas; for the 1960s model, rice fields were the land-use with the highest suitability (Table 2). Water bodies are particularly important for bullfrogs: tadpoles usually require 2 years for metamorphosis, and the adults are strongly dependent on waterbodies (Graves \& Anderson, 1987). In the study area, agriculture is associated to a dense network of ditches and reservoirs: bullfrogs can take advantage of the increased availability of permanent wetlands used for irrigation (Maret et al., 2006). Climatic suitability models have been deemed to predict suitability at a too coarse spatial scale, with the delineation of too large areas having limited usefulness for conservation actions (Heller \& Zavaleta, 2009). For example, based on climatic data, the whole study area had a high suitability for bullfrogs (Ficetola et al., 2007a). The integration of climatic data with land-use or other data recorded at finer scale can help to refine predictive models, and to focus on the areas where invasion risk is high at a spatial scale more appropriate for conservation.

While our models showed high sensitivity, they all tended to overpredict suitability: bullfrogs have never 
been recorded in large areas, which are predicted as suitable (Table 2, Fig. 1). These commission errors may have occurred for several reasons. First, the knowledge of bullfrog distribution is imperfect, because fine scale monitoring has not been performed over the whole study area. Efforts to improve our knowledge are currently ongoing (Ficetola et al., 2007b; Societas Herpetologica Italica, 2008), but several years will be needed for a complete knowledge of bullfrog distribution. Moreover, a model can fail because of the lack of key predictors affecting distribution, including the presence of predators/competitors. Our models were limited by the unavailability of some environmental variables in maps of past and future land-use. Furthermore, invasive species can be absent from suitable areas where they have not been introduced, or where they have not been able to disperse. In principle, bullfrogs might colonize the whole study area in a few generations, given their known dispersal ability (Austin et al., 2004). However, animal movements are strongly influenced by landscape features (Bélisle, 2005; Fahrig, 2007). Amphibians are particularly susceptible to fragmentation and to the presence of barriers (Cushman, 2006): the study area is strongly modified by humans, and elements such as roads and urbanization may have precluded colonization (Ficetola et al., 2007c).

Finally, the models developed for the three temporal steps were not identical. Two variables were consistently important in all models (i.e., elevation and cropland presence; Table 2). Conversely, rice fields were the most important variable in the 1960s, while they were unimportant in the subsequent temporal steps. The change of the explanatory power of rice field is probably related to strong modifications in agricultural practices. In Italy, rice cultivation traditionally requires the flooding of fields, and the presence of associated water reservoirs. Until the 1960s, the permanence of deep water within rice fields allowed farmers to perform aquaculture within the rice fields; bullfrogs and other amphibians took advantages of this environment (Albertini, 1970; Lupotto, 2005). In the last decades, agricultural practices strongly changed and the new technologies have modified the suitability of given land-use classes for many species. In fact, new rice cultivars require less water, with fields and irrigation network retaining water for shorter times and at lower depths, thus strongly reducing the ecological value of rice fields for amphibians (Lupotto, 2005). As a consequence, the simple presence of a land-use category (rice field in our case) can be a misleading indicator of habitat suitability, because key ecological attributes related to land management have been changed. This is a further example of the complexities and pitfalls linked to extrapolating model predictions in time.

\section{Integrating temporal variations of the environment}

The models including temporal changes of land-use showed a better prediction of the invasion dynamics and of the changes in distribution occurring through time. The global environment is changing at an unprecedented rate, and land-use changes have major impacts on biodiversity distribution (Sala et al., 2000). To date, most attention has been devoted on the effect of land-use change on native biodiversity. However, land-use is also important for the establishment and the spread of AIS. Land-use modifications have therefore important implications for the study and management of AIS.

First, land-use modifications can strongly affect the dynamics of invasive species. For example, in Model1960 bullfrogs were strongly associated to rice fields, and the model predicted high suitability in the East of the study area, where rice field density was high (Fig. 1b). However, the abundance of rice fields declined in the study area in the last decades of the 20th century, and this probably reduced the eastward bullfrog expansion. Both the land cover (i.e., the abundance of rice fields) and the land management practices (i.e., the way rice fields are cultivated) are not constant in time, and are subjected to the constraints of regional planning. Therefore, an integration of control strategies with the planning of land-use can have an important role for the management of invasive species, and to reduce their spread. Furthermore, ecological models are often used to predict invasion dynamics, with important applications in conservation strategies. However, species distribution models usually assume a static land-use. When these data are available, taking into account environmental modification can greatly improve model performance. Similarly, the combination of models with scenarios of future environmental changes can provide important insights that can be used to drive conservation strategies and regional planning. Our results therefore call for an increased consideration of temporal change of environmental variables when modelling distribution and suitability.

Our future land-uses do not constitute a 'prediction', but are the outcomes that can arise under different assumptions, and with a degree of coherence in the trends of future development (Rounsevell et al., 2006). Our models showed good performance in predicting historical changes of bullfrog distribution (Fig. 1), and our results were stable under various future scenarios (Fig. 2), suggesting that our conclusion on are robust. Nevertheless, projection of suitability models outside the area of calibration are always challenging (Guisan \& Thuiller, 2005), and should be considered with cautions. For example, the dynamic of the study area can be altered by unpredicted factors: human-related, climatic or biotic. 
Despite being human dominated, the study region is adjacent to some of the areas of Italy with the highest biodiversity irreplaceability values (Maiorano et al., 2007), particularly for freshwaters. These unique freshwater communities are threatened by the joint effects of land modifications and invasive species (Gherardi et al., 2008). As the spread of AIS is strongly related to landuse changes, an appropriate planning, with coordination between conservation and development policies, can help to achieve the management targets, with optimization of resources.

\section{Acknowledgements}

We thank two anonymous reviewers for comments on an earlier version of the manuscript. GFF was founded by funded by a scholarship of the University of Milano-Bicocca, and by a grant of the French Ministry for Research for young foreign researchers; WT and LM received support from the EU FP6 ECOCHANGE integrated project (Challenges in assessing and forecasting biodiversity and ecosystem changes in Europe, No: 066866 GOCE) and CM from EU FPE MARIE CURIE Programme (Biological invasions: patterns and processes. An integrative approach with the Bullfrog

R. catesbeiana in Canada and Europe, OIF No: 022190)

\section{References}

Albertini G (1970) Sulla diffusione della rana toro (Rana catesbeiana Shaw) importata nel mantovano. Atti e Memorie della Accademia di Agricoltura Scienze e Lettere di Verona, 20, 67-106.

Albertini G (1983) La Rana catesbeiana Shaw nella bassa pianura reggiano-modenese. Atti e Memorie della Accademia di Agricoltura Scienze e Lettere di Verona, 33, 125-154.

Albertini G, Lanza B (1987) Rana catesbeiana Shaw, 1802 in Italy. Alytes, 6, 117-129.

Austin JD, Lougheed SC, Boag PT (2004) Controlling for the effects of history and nonequilibrium conditions in gene flow estimates in northern bullfrog (Rana catesbeiana) populations. Genetics, 168, 1491-1506.

Beaumont L, Gallagher R, Thuiller W, Downey P, Leishman M, Hughes L (2009) Different climatic envelopes among invasive populations may lead to underestimations of current and future biological invasions. Diversity and Distributions, 15, 409-420.

Bélisle M (2005) Measuring landscape connectivity: the challenge of behavioral landscape ecology. Ecology, 86, 1988-1995.

Blaustein AR, Kiesecker JM (2002) Complexity in conservation: lessons from the global decline of amphibian populations. Ecology Letters, 5, 597-608.

Burnham KP, Anderson DR (2002) Model Selection and Multimodel Inference: A Practical Information-Theoretic Approach. Springer Verlag, New York.

Buttner G, Feranec J, Jaffrain G, Mari L, Maucha G, Soukup T (2004) The CORINE Land Cover 2000 project. EARSeL eProceedings, 3, 331-346.

Cushman SA (2006) Effects of habitat loss and fragmentation on amphibians: a review and prospectus. Biological Conservation, 128, 231-240.
Dendoncker N, Bogaert P, Rounsevell M (2006) A statistical method to downscale aggregated land use data and scenarios. Journal of Land Use Science, 1, 63-82.

Domenech R, Vila M, Pino J, Gesti J (2005) Historical land-use legacy and Cortaderia selloana invasion in the Mediterranean region. Global Change Biology, 11, 1054-1064.

Elith J, Graham CH, Anderson RP et al. (2006) Novel methods improve prediction of species' distributions from occurrence data. Ecography, 29, 129-151.

Engler R, Guisan A, Rechsteiner L (2004) An improved approach for predicting the distribution of rare and endangered species from occurrence and pseudo-absence data. Journal of Applied Ecology, 41, 263-274.

Evangelista PH, Kumar S, Stohlgren TJ, Jarnevich CS, Crall AW, Norman JB, Barnett DT (2008) Modelling invasion for a habitat generalist and a specialist plant species. Diversity and Distributions, 14, 808-817.

Fahrig L (2007) Non-optimal animal movement in humanaltered landscapes. Functional Ecology, 21, 1003-1015.

Falcucci A, Maiorano L, Boitani L (2007) Changes in land-use/ land-cover patterns in Italy and their implications for biodiversity conservation. Landscape Ecology, 22, 617-631.

Ficetola GF, Bonin A, Miaud C (2008) Population genetics reveals origin and number of founders in a biological invasion. Molecular Ecology, 17, 773-782.

Ficetola GF, Thuiller W, Miaud C (2007a) Prediction and validation of the potential global distribution of a problematic alien invasive species - the American bullfrog. Diversity and Distributions, 13, 476-485.

Ficetola GF, Coïc C, Detaint M, Berroneau M, Lorvelec O, Miaud C (2007b) Pattern of distribution of the American bullfrog Rana catesbeiana in Europe. Biological Invasions, 9, 767-772.

Ficetola GF, Garner TWJ, De Bernardi F (2007c) Genetic diversity, but not hatching success, is jointly affected by post glacial colonization and isolation in the threatened frog, Rana latastei. Molecular Ecology, 16, 1787-1797.

Ficetola GF, Thuiller W, Padoa-Schioppa E (2009) From introduction to the establishment of alien species: bioclimatic differences between presence and reproduction localities in the slider turtle. Diversity and Distributions, 15, 108-116.

Garner TWJ, Perkins MW, Govindarajulu P, Seglie D, Walker S, Cunningham AA, Fisher MC (2006) The emerging amphibian pathogen Batrachochytrium dendrobatidis globally infects introduced populations of the North American bullfrog, Rana catesbeiana. Biology Letters, 2, 455-459.

Gherardi F, Bertolino S, Bodon M et al. (2008) Animal xenodiversity in Italian inland waters: distribution, modes of arrival, and pathways. Biological Invasions, 10, 435-454.

Giovanelli JGR, Haddad CFB, Alexandrino J (2008) Predicting the potential distribution of the alien invasive American bullfrog (Lithobates catesbeianus) in Brazil. Biological Invasions, 10, 585-590.

Graves BM, Anderson SH (1987) Habitat suitability index models: bullfrog, US Fish and Wildlife Service Biological Report 82.

Guisan A, Thuiller W (2005) Predicting species distribution: offering more than simple habitat models. Ecology Letters, 8, 993-1009.

Heller NE, Zavaleta ES (2009) Biodiversity management in the face of climate change: a review of 22 years of recommendations. Biological Conservation, 142, 14-32. 
Hulme PE (2006) Beyond control: wider implications for the management of biological invasions. Journal of Applied Ecology, 43, 835-847.

Hurtt GC, Frolking S, Fearon MG et al. (2006) The underpinnings of land-use history: three centuries of global gridded land-use transitions, wood-harvest activity, and resulting secondary lands. Global Change Biology, 12, 1208-1229.

Jiménez-Valverde A, Lobo JM, Hortal J (2008) Not as good as they seem: the importance of concepts in species distribution modelling. Diversity and Distributions, 14, 885-890.

Kats LB, Ferrer RP (2003) Alien predators and amphibian declines: review of two decades of science and the transition to conservation. Diversity and Distributions, 9, 99-110.

Kraus F (2009) Alien Reptiles and Amphibians a Scientific Compendium and Analysis. Springer, Dordrecht.

Lanza B (1962) On the introduction of Rana ridibunda Pallas and Rana catesbeiana Shaw in Italy. Copeia, 1962, 642-643.

Le Maitre DC, Thuiller W, Schonegevel L (2008) Developing an approach to defining the potential distributions of invasive plant species: a case study of Hakea species in South Africa. Global Ecology and Biogeography, 17, 569-584.

Leemans R, Zuidema G (1995) Evaluating changes in land cover and their importance for global change. Trends in Ecology and Evolution, 10, 76-81.

Lever C (2003) Naturalized Amphibians and Reptiles of the World. Oxford University Press, New York.

Loo SE, Keller RP, Leung B (2007) Freshwater invasions: using historical data to analyse spread. Diversity and Distributions, 13, 23-32.

Lupotto E (2005) La sperimentazione agraria nella valorizzazione del ruolo multifunzionale del sistema risaia. In: Le rane in risaia: tradizione, scienza e risorsa, (eds Andreone F, di Trana CG, Lussich E, Tinarelli A, Varala GG), pp. 45-53. Vercelli, Provincia di Vercelli.

Maiorano L, Falcucci A, Boitani L (2008) Size-dependent resistance of protected areas to land-use change. Proceedings of the Royal Society B-Biological Sciences, 275, 1297-1304.

Maiorano L, Falcucci A, Garton EO, Boitani L (2007) Contribution of the Natura 2000 Network to Biodiversity Conservation in Italy. Conservation Biology, 21, 1433-1444.

Maret TJ, Snyder JD, Collins JP (2006) Altered drying regime controls distribution of endangered salamanders and introduced predators. Biological Conservation, 127, 129-138.

McKinney ML (2006) Urbanization as a major cause of biotic homogenization. Biological Conservation, 127, 247-260.

McKinney ML, Lockwood JL (1999) Biotic homogenization: a few winners replacing many losers in the next mass extinction. Trends in Ecology and Evolution, 14, 450-453.

Nakicenovic N, Swart R (2000) Emissions Scenarios: A Special Report of Working Group III of the Intergovernmental Panel on Climate Change. Cambridge University Press, Cambridge.

Nielsen C, Hartvig P, Kollmann J (2008) Predicting the distribution of the invasive alien Heracleum mantegazzianum at two different spatial scales. Diversity and Distributions, 14, 307-317.

Olden JD, Kennard MJ, Pusey BJ (2008) Species invasions and the changing biogeography of Australian freshwater fishes. Global Ecology and Biogeography, 17, 25-37.

Olden JD, Poff NL, Douglas MR, Douglas ME, Fausch KD (2004) Ecological and evolutionary consequences of biotic homogenization. Trends in Ecology and Evolution, 19, 18-24.
Pearson RG, Raxworthy CJ, Nakamura M, Peterson AT (2007) Predicting species distributions from small numbers of occurrence records: a test case using cryptic geckos in Madagascar. Journal of Biogeography, 34, 102-117.

Petit CC, Lambin EF (2002) Long-term land-cover changes in the Belgian Ardennes (1775-1929): model-based reconstruction vs. historical maps. Global Change Biology, 8, 616-630.

Phillips SJ, Anderson RP, Schapire RE (2006) Maximum entropy modeling of species geographic distributions. Ecological Modelling, 190, 231-259.

Phillips SJ, Dudík M (2008) Modeling of species distributions with Maxent: new extensions and comprehensive evaluation. Ecography, 31, 161-175.

Quian H, Ricklefs RE (2006) The role of exotic species in homogenizing the North American flora. Ecology Letters, 9, 1293-1298.

Ricciardi A (2007) Are modern biological invasions an unprecedented form of global change? Conservation Biology, 21, 329-336.

Rounsevell MDA, Reginster I, Araujo MB et al. (2006) A coherent set of future land use change scenarios for Europe. Agriculture Ecosystems and Environment, 114, 57-68.

Roura-Pascual N, Suarez AV, Goomez C, Pons P, Touyama Y, Wild AL, Peterson AT (2004) Geographical potential of Argentine ants (Linepithema humile Mayr) in the face of global climate change. Proceedings of the Royal Society of London B: Biological Sciences, 271, 2527-2534.

Sala OE, Chapin FS, Armesto JJ et al. (2000) Biodiversity - global biodiversity scenarios for the year 2100. Science, 287, 1770-1774.

Societas Herpetologica Italica. (2008) Osservatorio Erpetologico Italiano. Acta Herpetologica, 3, 83-84.

Spangenberg JH (2007) Integrated scenarios for assessing biodiversity risks. Sustainable Development, 15, 343-356.

Strayer DL, Evinver VT, Jeschke JM, Pace ML (2006) Understanding the long-term effects of species invasions. Trends in Ecology and Evolution, 21, 645-651.

Thuiller W (2007) Climate change and the ecologist. Nature, 448, 550-552.

Thuiller W, Richardson DM, Pysek P, Midgley GF, Hughes GO, Rouget M (2005) Niche-based modelling as a tool for predicting the risk of alien plant invasions at a global scale. Global Change Biology, 11, 2234-2250.

Urban MC, Phillips BL, Skelly DK, Shine R (2008) A toad more traveled: the heterogeneous invasion dynamics of cane toads in Australia. The American Naturalist, 171, E134-E148.

Vallecio S, Brotons L, Thuiller W (2009) Dangers of predicting bird species distributions in response to land-cover changes: the role of dynamic processes. Ecological Applications, 19, 538-549.

Ward DF (2007) Modelling the potential geographic distribution of invasive ant species in New Zealand. Biological Invasions, 9, 723-735.

Wisz MS, Hijmans RJ, Li J, Peterson AT, Graham CH, Guisan A (2008) Effects of sample size on the performance of species distribution models. Diversity and Distributions, 14, 763-773.

Yiming L, Zhengjun W, Duncan RP (2006) Why islands are easier to invade: human influences on bullfrog invasion in the Zhoushan archipelago and neighboring mainland China Oecologia, 148, 129-136. 